\title{
COMPARISON OF MILK PRODUCTION OF THE PROGENY OF BLAD-CARRIER AND HEALTHY HOLSTEIN BULLS IN HUNGARY
}

\author{
Ágnes JÁNOSA ${ }^{1 *}$, B. BARANYAI ${ }^{2}$ and J. DOHY ${ }^{1}$ \\ ${ }^{1}$ University of Agricultural Sciences, Faculty of Agriculture, Páter K. u. 1, H-2103 \\ Gödöllö, Hungary; ${ }^{2}$ Agricultural Biotechnology Centre, H-2001 Gödöllő, Hungary
}

(Received November 23, 1998; accepted February 10, 1999)

\begin{abstract}
'Bovine Leukocyte Adhesion Deficiency' (BLAD) is a recessive monofactorial, lethal inheritable defect occurring in Holstein-Friesian cattle and often passed on by well-known top bulls. The aim of this study was to find a relationship between the BLAD genotype of bulls, their genetic evaluation for milk and their daughters' milk production. BLAD-carrier and healthy bulls were compared on the basis of their breeding value published in November 1997. The first 100 bulls ranked according to the Total Production Index (TPI) were used, including nine BLAD carriers with 2,835 daughters and 77 healthy sires with 21,950 female progenies. For 14 bulls the BLAD genotype was not indicated. The healthy animals significantly outperformed the BLAD carriers, which result contradicts our earlier findings (Dohy et al., 1996; Jánosa and Dohy, 1997). In a BLAD elimination programme, the identification of BLAD carriers and properly planned mating are of great importance in order to avoid 'inter se' mating of BLAD-carrier top animals which can be of significant influence in Holstein breeding.
\end{abstract}

Key words: BLAD, carrier, genetic defect, progeny testing, Holstein, bull

The development of artificial insemination (AI) enabled the advent of modern dairy cattle breeding practices. However, the worldwide use of genetic materials from progeny-tested and top-ranked bulls resulted in the shallowing of the genetic pool. The increased degree of genetic relatedness among top animals has facilitated the spread of recessive genetic diseases such as Bovine Leukocyte Adhesion Deficiency (BLAD).

BLAD, formerly named Bovine Granulocytopathy Syndrome, BGS (Gerardi, 1996) and discovered in the United States in 1989, is an autosomal monofactorial recessive lethal genetic defect of Holstein cattle, which is analogous to leukocyte adhesion deficiency (LAD) of humans. Calves homozygous for BLAD genes rapidly succumb to a general infection occurring in the herd, and they are easily affected by otherwise non-pathogenic microorganisms. The symptoms are

"E-mail: dohy@fau.gau.hu; Fax: (36-28) 410-804 
rather diverse. Homozygous calves, if they survive the first year of life, will show retarded growth and suffer from never-ending inflammations and infections. Although they may reach maturity, they will never be in heat. Physical retardation is a typical symptom of such animals characterised by a big head, slow movement and uninterested behaviour. The symptoms often appear within one or two months after birth. These include red and sensitive areas on the epithelium, ulcers in the mouth and pharynx, gingival atrophy, excessive production of saliva, munching, swallowing difficulties, slow regurgitation and rumen movements that result in diarrhoea. These symptoms are accompanied by diseases of the lungs and upper respiratory tract. In half of the cases a temporary or chronic fever is present. Unlike the canine or human form of LAD, inflammation of the navel or of the joints is not characteristic of BLAD (Stöber, 1996).

The symptoms of leukocytoses of non-BLAD origin are less severe. Compared to other neutrophil leukocytoses of non-BLAD origin (oNL), retarded development is more common among BLAD patients, and their daily weight gain is also lower (BLAD: 0.3, oNL: 0.5, healthy: $0.6 \mathrm{~kg}$ ). BLAD patients show a higher incidence of disorders affecting the proximal part of the digestive tract, the upper respiratory tract, the eyes and the ears, they are more susceptible to ectoparasites, and their wounds heal much more slowly (Stöber, 1996).

The genetic background of the disorder was described by Shuster et al. (1992). The granulocytes synthesize proteins stored in granules in the cytoplasm. Out of the granulocytes, the phagocytic neutrophils containing granules with microbicidal proteins and digestive enzymes are of relevance to BLAD. If alarmed against alien infectious agents, these leukocytes go through the wall of the blood vessels to the tissues and release their granular contents via exocytosis. They have membrane receptors to recognize and bind pathogens for phagocytosis (Williams, 1990; cit. Gerardi, 1996). During their migration, their connection to the endothelial cells is provided by special, so-called $\beta_{2}$ integrin surface proteins. Without $\beta_{2}$ integrins, neutrophils are unable to enter the tissues. According to Gerardi (1996), the $\beta_{2}$ integrins include leukocyte function associated antigen (LFA-1), macrophage antigen (Mac-1) and p150,95 glycoproteins that consist of individual $\alpha$ subunits (CD11a, CD11b and CD11c, respectively) and a common $\beta$ subunit (CD18). Since the association of CD11 and CD18 subunits is a prerequisite of the expression of the $\beta_{2}$ integrin, any damage to CD18 makes the expression of $\beta_{2}$ integrin impossible (Shuster et al., 1992). In homozygous animals, the level of Mac-1 decreases (Fésüs et al., 1997) and only some $2 \%$ of the normal level of CD18 can be detected (Kehrli et al., 1992; cit. Fésüs et al., 1997).

A point mutation of the gene encoding CD18 is responsible for the development of the disease (Shuster et al., 1992; Fésüs et al., 1997). As a result, the 
CD18 subunit fails to connect to CD11 and the leukocytes lose their ability to penetrate the wall of blood vessels and migrate to the infected tissues.

All the pedigrees of BLAD carriers and BLAD patients contain a bull named 'Osborndale Ivanhoe' born in 1952. He was called the 'Father of the Holstein breed' after the thousands of registered sons and daughters he sired. This bull was a BLAD carrier and because his progeny had excellent milk production and transmitting ability, the recessive BLAD allele of the gene has been dispersed all over the world (Shuster et al., 1992). The strong selection, the use of a rather small population of top bulls, and the emergence and application of novel biotechnological methods all contributed to its rapid expansion. Thus it is no wonder that BLAD is the most widespread of all the genetic defects of cattle (Shuster et al., 1992).

The presence of the allele can safely be detected from blood, semen or hair roots using polymerase chain reaction (PCR) techniques such as restricted fragment length polymorphism (PCR-RFLP) or ligase chain reaction (PCR-LCR) (Shuster et al., 1992; Batt et al., 1994; Zsolnai and Fésüs, 1996). In animal breeding it is difficult to select against a recessive allele since the majority of such alleles are present in the population in an invisible, heterozygous form. Thus, in a survey, 127 animals proved to be carriers (heterozygotes) and only four were phenotypically affected (homozygotes, all alleles defective) out of 1179 animals screened for BLAD, while 1048 proved to be free of BLAD (Förster, 1997). Without diagnosing the genes, only the eight alleles - those of the homozygotes - could have been detected and selected out of the 135 defective alleles, while 127 heterozygous alleles remained undetected and, therefore, unselected (Förster, 1997). Owing to the reliability of modern detection methods, theoretically BLAD could be eradicated. However, experts are divided as to whether a total eradication of the carriers is really needed. Thus, the carriers listed in the bull catalogues are marked with the letters 'BL' (Fésüs et al., 1997).

The references show that this topic has not been thoroughly discussed. Fésüs et al. (1997) gave a detailed overview of publications dealing with possible connections between BLAD and productivity. The findings are rather contradictory, as various research groups found different relationships between BLAD and each of the production traits. The feed conversion of healthy bulls was superior to that of carriers by 0.07 Scandinavian feed units (SFU) per $\mathrm{kg}$ (Jörgensen and Madsen, 1994; cit. Fésüs et al., 1997). No significant relationship was found between BL genotype and its possible effects on five production and 15 type traits. According to researchers, this shows that the spread of the BLAD allele is due to a genetic drift caused by the shallowing genetic pool, rather than by its relationship with production or other traits (Boichard and Amigues, 1995; cit. Fésüs et al., 1997). Dohy et al. (1996) found significantly higher milk, protein and fat yield in daughters of BLAD-carrier bulls. In another study, the TPI (Total Production Index) and INET (a Dutch selection index) of 
BL groups proved to be better than those of TL genotypes in the Hungarian and Dutch Holstein-Friesian populations surveyed (Jánosa and Dohy, 1997).

American researchers have found the BLAD allele to be detrimental to milk, protein and fat yield and percentage and to productive life and milk somatic cell counts (Powell et al., 1996). Thus any selection against BLAD does not exert a negative influence on production. However, four years after launching the BLAD elimination programme, 44 carriers, of otherwise improving effect, were still in active service. This explains why carriers excelled non-carriers in the genetic evaluation, but it would be misleading to conclude that bulls with a BL genotype are necessarily improvers (Powell et al., 1996; cit. Fésüs et al., 1997).

The rather contradictory results cited herein and the significance of this disease warranted further experiments, the results of which are reported in this paper.

\section{Materials and methods}

Top Hungarian BLAD-carrier and healthy Holstein-Friesian bulls were compared on the basis of their breeding value published in November 1997. In the survey, the first 100 bulls ranked according to their Total Production Index (TPI) (Bognár, 1997) were used. The BLAD genotype was indicated in 86 cases only. Out of these, nine animals proved to be carriers, and 77 were free of the BLAD gene. The distribution of the genotypes was calculated.

A comparison was made between the results of genetic evaluation for milk, milk fat and milk protein production and the phenotypic values of the same traits of some 21,950 and 2,835 progenies sired by healthy and affected bulls, respectively. Data processing included analysis of variance with SPSS of ANOVA.

\section{Results and conclusion}

The distribution of BLAD genotypes shown in Table 1 implies that ca. 10\% of the top sires are affected. The ranking of carriers was also investigated. From the facts that the best bulls are favoured and used more frequently by breeders, and that there was only one carrier (ranked $12^{\text {th }}$ ) among the first 40 sires, it can be concluded that other BLAD carriers do not exert a significant genetic effect on their progeny.

Table 1

BLAD genotype frequencies of 86 Holstein-Friesian bulls

\begin{tabular}{lcc}
\hline \multicolumn{1}{c}{ Alleles } & No. of animals & Frequency $(\%)$ \\
\hline Healthy (TL) & 77 & 89.53 \\
BLAD carrier (BL) & 9 & 10.47 \\
\hline
\end{tabular}


The frequency of BLAD allele (5.23\%) shown in Table 2 is half the frequency shown in Table $1(10.47 \%)$ due to heterozygosity of the recessive gene.

Table 2

BLAD allele frequencies of 86 Holstein-Friesian bulls

\begin{tabular}{lc}
\hline \multicolumn{1}{c}{ Alleles } & Frequency (\%) \\
\hline Healthy (TL) & 94.77 \\
BLAD carrier (BL) & 5.23
\end{tabular}

The evaluation of relationships, if any, between BLAD genotype and production traits was based on the bulls' genetic evaluation (progeny test) for milk yield, fat yield and protein yield (Table 3). As regards the milk yield, healthy bulls significantly outperformed BLAD carriers $(791 \mathrm{~kg}$ and $774 \mathrm{~kg}$, respectively). In milk fat production, healthy bulls performed better than carriers $(27.8 \mathrm{~kg}$ and $25.6 \mathrm{~kg}$, respectively), while carriers produced slightly more milk protein $(23.6 \mathrm{~kg})$ than unaffected bulls $(23.5 \mathrm{~kg})$. Nevertheless, only the genetic evaluation of milk yield showed significant differences $(\mathrm{P}<0.05)$.

Table 3

Genetic evaluation of healthy and BLAD-carrier bulls for milk yield, fat yield and protein yield (mean \pm standard deviation)

\begin{tabular}{lccc}
\hline \multirow{2}{*}{ Alleles } & \multicolumn{3}{c}{ Results of genetic evaluation } \\
\cline { 2 - 4 } & $\begin{array}{r}\text { Milk, } \mathrm{kg} \\
\bar{x} \pm \mathrm{SD}\end{array}$ & $\begin{array}{c}\text { Fat, } \mathrm{kg} \\
\bar{x} \pm \mathrm{SD}\end{array}$ & $\begin{array}{c}\text { Protein, } \mathrm{kg} \\
\bar{x} \pm \mathrm{SD}\end{array}$ \\
\hline Healthy (TL) & $791 \pm 102$ & $27.8 \pm 3.7$ & $23.4 \pm 2.5$ \\
BLAD carrier (BL) & $774 \pm 67$ & $25.6 \pm 2.0$ & $23.6 \pm 2.2$ \\
\hline
\end{tabular}

The average production of the sires' daughters was compared using the same traits (milk, fat, protein yield). The results are presented in Table 4. The daughters sired by healthy bulls significantly outperformed the progeny of carriers in all three traits.

From the results it can be concluded that currently BLAD-carrier sires do not play a significant role among Hungarian top bulls. Their number continues to decrease as their performance is worse than that of healthy bulls and, therefore, BLAD-carrier sires are less likely to become popular. Similar results were published by Fésüs et al. (1998). In their analysis, no significant performance differences were found between carrier and healthy cows. In fact, breeders select against carriers to avoid the unwanted symptoms of the BLAD gene. 
Table 4

Milk, fat and protein yield of the progeny of healthy and BLAD-carrier bulls (mean \pm standard deviation)

\begin{tabular}{lrcc}
\hline \multirow{2}{*}{ Alleles } & \multicolumn{3}{c}{ Yield } \\
\cline { 2 - 4 } & $\begin{array}{r}\text { Milk, kg } \\
\bar{x} \pm \mathrm{SD}\end{array}$ & $\begin{array}{c}\text { Fat, kg } \\
\bar{x} \pm \mathrm{SD}\end{array}$ & $\begin{array}{c}\text { Protein, } \mathrm{kg} \\
\bar{x} \pm \mathrm{SD}\end{array}$ \\
\hline Healthy (TL) & $7445 \pm 494$ & $279.7 \pm 9.9$ & $243.4 \pm 10.0$ \\
BLAD carrier (BL) & $7201 \pm 262$ & $268.7 \pm 6.3$ & $233.6 \pm 7.0$ \\
\hline
\end{tabular}

The results are inconsistent with the authors' earlier works, in which they found that BLAD carriers outperformed their healthy mates (Dohy et al., 1996; Jánosa and Dohy, 1997). This draws attention to the importance of a perpetual screening of the genetically most influential sires and of the comparison of sires with different genotypes when choosing the right sire to avoid mating of BLAD carriers. This is also supported by the fact that the Holstein-Friesian bull with the highest breeding value (named '12991 LOBOGÓ OSADO', TPI Score published in May 1998: 1286) is a BLAD carrier.

\section{References}

Batt, C. A., Wagner, P., Wiedmann, M., Luo, J. and Gilbert, R. (1994): Detection of bovine leukocyte adhesion deficiency by nonisotopic ligase chain reaction. Anim. Genet. 25, 95-98.

Bognár, L. (1997): Performance of Holstein sires in Hungary (in Hungarian). Publication of the National Association of Hungarian Holstein-Friesian Breeders, 1997.

Boichard, D. and Amigues, Y. (1995): Investigation on possible linkage between the BLAD gene and a QTL for production or type traits in Holstein cattle. $46^{\text {th }}$ Ann. Meet. EAAP, Prague, Czech Republic.

Dohy, J., Jánosa, Á. and Vági, J. (1996): Evaluation of BLAD carrier and non BLAD carrier top bulls. $47^{\text {th }}$ Ann. Meet. EAAP, Lillehammer, Norway, Proc. p. 307.

Fésüs, L., Zsolnai, A. and Anton, I. (1997): Marker assisted selection in livestock. $2^{\text {nd }}$ Paper: Bovine Leukocyte Adhesion Deficiency (BLAD) (in Hungarian). Állatteny. és Takarm. 6, 481-492.

Fésüs, L., Zsolnai, A., Anton, I., Bárány, I. and Bozó, S. (1998): Effect of BLAD-genotype on the production traits in the Hungarian Holstein-Friesian population (in Hungarian). Holstein Magazin (Publication of the National Association of Hungarian Holstein-Friesian Breeders) $1,29-31$.

Förster, M. (1997): Genomanalyse. In: Kräußlich, H. and Brem, G. (eds) Tierzucht und Allgemeine Landwirtschaftslehre für Tiermediziner, Ferdinand Enke Verlag, Stuttgart, p. 95.

Gerardi, A. S. (1996): Bovine Leukocyte Adhesion Deficiency: A brief overview of a modern disease and its implications. Acta Vet. Hung. 44, 1-8.

Jánosa, Á. and Dohy, J. (1997): Comparison of BLAD carrier and non BLAD carrier top bulls. J. Anim. Sci. 75, Suppl. 1, 152. 
Jörgensen, J. N. and Madsen, P. (1994): Association between BLAD and performance test results in Danish Holstein-Friesian. $45^{\text {th }}$ Ann. Meet. EAAP, Edinburgh, Scotland, G. 1. 11. Proc., 81.

Kehrli, M. E., Shuster, D. E. and Ackermann, M. R. (1992): Leukocyte adhesion deficiency among Holstein cattle. Cornell Vet. 82, 103-109.

Powell, R. L., Norman, H. D. and Cowan, C. M. (1996): Relationship of bovine leukocyte adhesion deficiency with genetic merit for performance traits. J. Dairy Sci. 79, 895-899.

Shuster, D. E., Kehrli, M. E., Ackermann, M. R. and Gilbert, R. O. (1992): Identification of prevalence of a genetic defect that causes leukocyte adhesion deficiency in Holstein cattle. Proc. Nat. Acad. Sci., USA, 89, 9225-9229.

Stöber, M. (1996): Clinical symptomatology of bovine adhesion deficiency (BLAD) (in Hungarian, with English abstract). Magyar Állatorvosok Lapja 3, 152-154.

Williams, W. J. (ed.) (1990): Hematology. $4^{\text {th }}$ edition. McGraw-Hill, Inc., New York, pp. 761, 770, $824-826$.

Zsolnai, A. and Fésüs, L. (1996): Simultaneous analysis of bovine K-casein and BLAD alleles by multiplex PCR followed by parallel digestion with two restriction enzymes. Anim. Genet. 27, 207-209. 